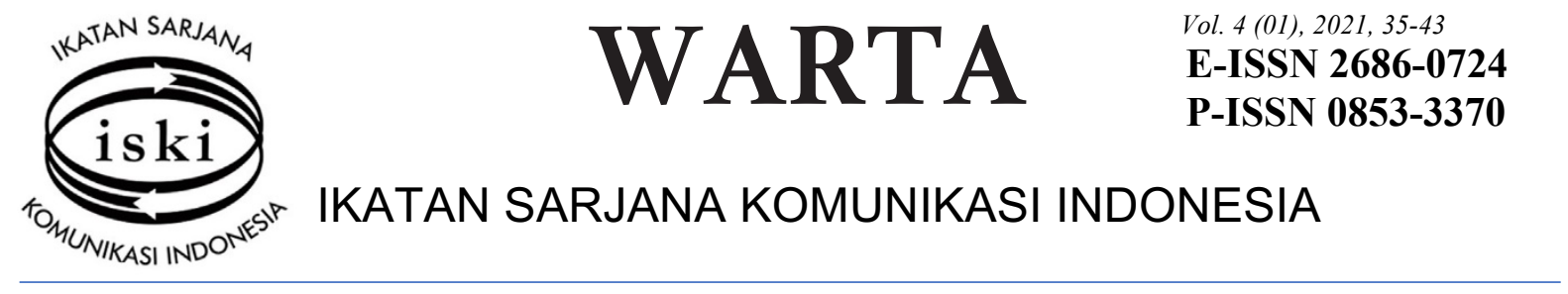

\title{
Tinjauan Pelanggaran Kode Etik Jurnalistik dalam Pemberitaan Prostitusi Online di Surabaya
}

\author{
http://dx.doi.org/10.25008/wartaiski.v4i1.108
}

\author{
Ahmad Khairul Nuzuli ${ }^{*}$, Wahyu Krisitian Natalia ${ }^{2}$, Wiwid Adiyanto ${ }^{3}$ \\ ${ }^{1}$ Institut Agama Islam Negeri Kerinci \\ Jl. Kapten Muradi, Sungai Liuk, Kota Sungai Penuh, Kerinci 37112, Jambi - Indonesia \\ ${ }^{2,3}$ Universitas Amikom Yogyakarta \\ Jl. Ring Road Utara, Ngringin, Condongcatur, Kec. Depok, Yogyakarta 55281- Indonesia \\ *e-mail korespondensi: ahmadkhairulnuzuli@iainkerinci.ac.id
}

Submitted: 04/03/2021, Revised: 28/05/2021, Accepted: 15/06/2021

Accredited by Kemristekdikti No. 30/E/KPT/2019

\begin{abstract}
Lot to slightly influence the way the public views it. Sex reporting is a practice and increases circulation, but on the other hand, this affects the public viewpoint that does not empathize with sexual crimes. One of the hot news in early 2019 was the VA online prostitution case, and one of the media that contained this information was Jatim.tribunnews.com. This study aims to see how the application of journalistic ethics to VA's online prostitution news on Jatim.tribunnews.com. This research uses a descriptive qualitative method and 62 news items were studied starting January 21-31 2019. The results of the study show that Jatim.tribunnews.com. violates journalistic ethics, especially in terms of loading the identities of women involved in sexual crime cases and unbalanced coverage
\end{abstract}

Keywords: Journalistic ethics, online media, gender sensitive, online prostitution, mass media

\begin{abstract}
Abstrak
Cara pandang media atas sebuah peristiwa yang diberitakannya dapat mempengaruhi cara pandang masyarakat atas fakta pemberitaan tersebut. Pemberitaan seks merupakan sebuah peristiwa yang dapat menaikkan oplah sebuah media, namun disisi lain ini berita itu dapat berpengaruh pada cara pandang masyarakat yang tidak berempati pada kejahatan seksual. Salah satu pemberitaan yang hangat pada awal tahun 2019 adalah kasus prostitusi online VA. Salah satu media yang memuat iniformasi kasus itu adalah Jatim.tribunnews.com. Penelitian ini bertujuan untuk melihat bagaimana penerapan etika jurnalistik pada pemberitaan prostitusi online VA di Jatim.tribunnews.com. Penelitian ini mengunakan metode deskriptif kualitaif dan terdapat 62 berita yang diteliti terhitung 21-31 Januari 2019. Hasil penelitian menujukkan bahwa Jatim.tribunnews.com melanggar etika jurnalistik terutama dalam hal pemuatan indetitas perempuan yang terlibat dalam kasus kejahatan seksual.
\end{abstract}

Kata Kunci: etika jurnalistik, media online, sensitif gender, prostitusi online, media massa

\section{PENDAHULUAN}

Di era kemajuan teknologi informasi saat ini, masyarakat mengakses berita secara online. Hal ini bisa terlihat dari data riset Nielsen mengenai Media Costumer View Pada tahun 2017 yang memaparkan penetrasi penggunaan media, $44 \%$ sudah menggunakan internet. Selain itu menurut Dailysosial.id, pada tahun 2017, sebanyak 90,22\% masyarakat Indonesia menggunakan media online untuk mencari berita (Nielsen, 2017).

Sebagai media popular dan besar, portal berita tribunnews.com dalam pemberitaannya mempengaruhi cara pandang masyarakat, termasuk dalam memandang isu-isu gender. Menurut Rossy (2015), berita seks merupakan salah satu jenis pemberitaan yang sangat laku. Rossy juga 
menambahkan, berita seks akan memancing imajinasi pembaca dan tidak berempati pada korban kejahatan seksual.

Seks dan kekerasan menjadi isu yang paling laku dan mempunyai rating tinggi dalam pemberitaan, namun tidak mencerdaskan masyarakat. Menurut Artini dkk (2019) terdapat tiga tema paling banyak diliput media, yakni pemerkosaan, pelecehan seksual, dan penjualan perempuan.

Cara penyajian berita oleh wartawan terkait pelecehan seksual menjadi salah satu persoalan penting di media. Sudut pandang dan penyajian berita akan memberi cara pandang kepada masyarakat terkait isu yang berhubungan dengan perempuan dan seksual. Lan (2002) mengatakan, pemberitaan kejahatan seksual di media saat ini didominasi oleh bias gender. Realitas perempuan di dalam pemberitaan media tidak dianggap mencerminkan realitas perempuan di masyarakat.

Pemberitaan harus mendukung penghapusan tayangan kekerasan pada perempuan yang menampilkan informasi tidak berimbang, karena tidak sesuai dengan Hak Asasi Manusia (HAM) sebagaimana telah dideklarasikan oleh Persatuan Bangsa-Bangsa mengenai penghapusan kekerasan terhadap perempuan (AJI, 2015). Hal ini menujukkan bahwa keberimbangan pemberitaan terhadap kekerasan perempuan telah menjadi isu global dan harus dibenahi.

Meskipun berbagai peraturan dibuat untuk mengurangi kekerasan seksual, namun pada kenyataannya kekerasan terhadap perempuan tetap tinggi. Data Komnas Perempuan menyatakan, pada 2011 terdapat 400,939 kasus kejahatan seksual antara lain pemerkosaan, perdagangan perempuan, pelecehan, penyiksaan, dan ekploitasi seksual (AJI, 2011).

Dalam melakukan tugas jurnalistik di lapangan, wartawan tunduk pada Pasal 5 Kode Etik Jurnalistik yang berbunyi: "Wartawan Indonesia tidak menyebutkan dan menyiarkan indentitas korban kejahatan susila". Identias yang dimaksud adalah segala hal yang memudahkan orang untuk melacak data diri korban misalnya nama, identitas orang tua, alamat rumah ataupun alamat kantor korban.

Pelaporan indetitas korban dalam pemberitaan akan menimbulkan rasa shock, trauma dan ketakutan. Hal ini karena korban telah kehilangan privasi, merasa dirinya telah ternoda dan tidak mempunyai harga diri. Dampak ini harus menjadi perhatian bagi media saat meliput kasus kejahatan seksual (AJI, 2011).

Wigjosoebroto (1995) mengatakan, kejahatan seksual merupakan aktivitas seksual yang berlebihan, dan tidak memiliki tujuan untuk melakukan reproduksi. Adapun kejahatan seksual antara lain pelacuran (prostitusi), perzinahan, kumpul kebo, pencabulan, pemerkosaan. Jika dikaitkan dengan penelitian ini, Pratiwi (2010) mengatakan, berkaca dari kasus artis VA, perempuan rentan menjadi korban prositusi. Pratiwi menjelaskan, VA merupakan korban kejahatan seksual akibat dampak kemiskinan struktural.

Indainanto (2020) mengatakan, sesungguhnya ada upaya menormalisasi kekerasan terhadap wanita di media, termasuk dalam kasus kejahatan seksual, namun adanya dominasi sumber berita yang mengarah, menyalahkan dan menyudutkan perempuan, membuat pemberitaan terkait kekerasan seksual cendrung tidak berimbang.

Lan (2002) mengatakan, pada dasarnya bias gender pada media terlihat pada produk pemberitaan yang mereka hasilkan. Selain itu sikap wartawan terhadap perempuan juga menjadi indikator penting. Sebenarnya, banyak wartawan telah dibekali kompetensi untuk menyajikan pemberitaan yang responsif gender. Dewan Pers telah menerbitkan Seruan Dewan Pers No 189 Tahun 2013 terkait pemberitaan kejahatan susila dan menekankan pentingya Pasal Pasal 5 Kode Etik Jurnalistik dipatuhi.

Dalam seruan itu, Dewan Pers meminta para wartawan agar serius dalam melindungi korban kejahatan susila yang umumnya adalah perempuan dan anak. Tujuan serutan ini untuk menghindari korban mengalami kejahatan kembali, dan memperkecil dampak trauma yang dialami korban.

Etika sangat diperlukan saat melakukan tugas jurnalistik, agar bisa menjadi panduan moral bagi wartawan dalam menulis pemberitaan. Pada dasarnya, jurnalis ikut andil dalam mengendalikan opini pemberitaan (Afridah, 2014). Selain itu wartawan juga menganggap etika jurnalistik itu penting. Namun, penerapannya di lapangan sangat minim. Inilah yang menjadi permasalahan wartawan sekarang ini (Prigusnanto, 2017).

Tribunnews.com merupakan salah satu situs media online milik Kompas. Menurut data pemeringatan website dunia, Alexa.com, Tribunnews.com merupakan situs berita nomor satu di Indonesia. Tribunnews.com merupakan salah satu rujukan utama masyarakat Indonesia dalam mengkonsumsi media online. 
Pemberitaan prostitusi online dengan tersangka artis VA merupakan salah satu pemberitaan yang diangkat oleh Jatim.tribunnews.com pada awal Januari 2019 dengan menghadirkan 62 berita dari tanggal 21 hingga 31 Januari 2019. Terkait dengan itu, penelitian ini ingin melihat bagaimana gambaran implementasi kode etik jurnalistik di Jatim.tribunnews mengenai prostitusi online artis VA.

Jatim.tribunnews.com sebagai media online terbesar di Indonesia selayaknya menyajikan berita dengan mematuhi kode etik jurnalistik dalam peliputan kekerasan seksual sebab cara penyajian berita merupakan hal terpenting dalam media massa. Pasalnya, penyajian berita dapat mempengaruhi cara pandang masyarakat terhadap sebuah permasalahan.

Penelitian yang dilakukan I Gusti Ayu dengan judul "Analisis isi berita kekerasan seksual tribunnews.com" menyatakan tribunnews cenderung memberitakan kekerasan seksual. Selain itu, jurnalis tribunnews.com cenderung memberitakan kekerasan seksual dengan menggunakan diksi yang bias. Hal penting lainnya dari penelitian itu adalah, dalam melakukan kegiatan jurnalistik, tribunnews.com masih mengungkapkan identitas korban kekerasan seksual.

Penelitian lainnya dilakukan Maudy Fitri Hutami dan Nuryah Asri Sjafirah dengan judul "Framing Media Online Tribunnews. Com terhadap sosok perempuan dalam berita video pornografi di Depok". Studi itu menyatakan tribunnews.com melanggar Kode Etik Jurnalistik dan melanggar privasi korban saat memberitakan peristiwa kekerasan seksual.

Berdasarkan latar belakang masalah, maka penelitian ini merumuskan pemasalahan sebagai berikut: Bagaimana implementasi Kode Etik Jurnalistik pada pemberitaan prostitusi online VA di Jatim.Tribunnews.com?

\section{KERANGKA TEORI}

Kode Etik Jurnalistik merupakan landasan moral bagi wartawan dalam menjalankan tugas jurnalistiknya. Hal ini bertujuan untuk menegakkan integritas dan profesionalitas wartawan dalam menyajikan berita. Kode etik jurnalistik terkait dengan pemberitaan tercantum pada Pasal 2 Kode Etik Wartawan Indonesia. Pasal itu menyatakan: "Wartawan Indonesia menempuh cara-cara yang profesional dalam melaksanakan tugas jurnalistik". Dalam pesafsirannya diuraikan, wartawan dilarang menampilkan indetitas narasumber, harus memberitakan secara berimbang, serta menghormati pengalaman traumatik narasumber dalam pemberitaan terkait kekerasan seksual.

Selain itu, Pasal 5 Kode Etik Jurnalistik berbunyi: "Wartawan Indonesia tidak menyebutkan identitas korban kejahatan susila dan tidak menyebutkan identitas anak yang menjadi pelaku kejahatan". Penafsiran Pasal 5 itu menekankan wartawan harus melindungi indentitas korban kekerasaan seksual yang menjadi pelaku atau korban kejahatan. Indentitas yang dimaksud adalah segala data yang mempermudah orang mengetahui dan melacak pelaku maupun korban kejahatan seksual.

Dalam banyak kasus, wartawan masih sering mengungkap identitas korban kejahatan susila seperti menulis nama korban, nama orangtua, nama dan alamat rumah, kampung, desa, kantor atau nama sekolah para korban kejahatan seksual (Dewan Pers, 2013). Dewan Pers (2013) menambahkan, wartawan harus hati-hati dan bijaksana dalam pemuatan nama inisial korban. Dewan Pers menganjurkan penggunaan sebutan "seorang perempuan", "seorang anak" atau "korban" untuk menggambarkan identitas korban.

Selain itu, Undang-undang No 40 Tahun 1999 tentang Pers pada Pasal 2 menyatakan: "Wartawan Indonesia menempuh cara-cara profesional dalam menjalankan tugas jurnalistik". Pasal ini berhubungan dengan cara kerja wartawan di lapangan dan bagaimana wartawan harus menyajikan pemberitaan yang berimbang, termasuk dalam menyajikan informasi yang tidak menimbulkan rasa traumatik pada korban.

\section{METODE PENELITIAN}

Penelitian ini menggunakan pendekatan analisis isi deskriptif kuantitaif. Menurut Sugiyono (2018), analisis deskriptif adalah cara analisis yang menggambarkan kondisi data di lapangan seperti apa adanya untuk mendeskripsikan hasil/objek penelitian.

Data primer berupa dokumen pemberitaan terkait prostitusi online artis VA di Jatim,Tribunews.com selama Januari 2019. Terdapat 62 pemberitaan yang dijadikan sampel dalam penelitian ini. Huberman dan Miles (dalam Berg \& Lune, 2012) mengatakan, tahap analisis dalam penelitian terdiri atas tiga alur secara bersamaan yaitu reduksi data, penyajian data, dan menarik kesimpulan/verifikasi. Adapun daftar berita yang di teliti dalam penelitian ini adalah sebagai berikut: 
Tabel 1. Daftar Berita Prostitusi Online VA Selama Januari 2019

\begin{tabular}{|c|c|c|}
\hline No & Judul & Link \\
\hline 1 & $\begin{array}{l}\text { VA Tersangka Kasus Prostitusi, Adik } \\
\text { Almarhum Ibunya Beri Dukungan: Dia Merasa } \\
\text { Sendirian }\end{array}$ & $\begin{array}{l}\text { https://jatim.tribunnews.com/2019/01/21/vanessa- } \\
\text { angel-tersangka-kasus-prostitusi-adik-almarhum- } \\
\text { ibunya-beri-dukungan-dia-merasa-sendirian }\end{array}$ \\
\hline 2 & $\begin{array}{l}\text { VA Bakal Diperiksa Terkait Prostitusi Artis, } \\
\text { Polda Jatim Beri Klarifikasi Soal Penahanan }\end{array}$ & $\begin{array}{l}\text { https://jatim.tribunnews.com/2019/01/21/vanessa- } \\
\text { angel-bakal-diperiksa-terkait-prostitusi-artis-polda- } \\
\text { jatim-beri-klarifikasi-soal-penahanan }\end{array}$ \\
\hline 3 & $\begin{array}{l}\text { VA Mangkir dari Panggilan Polda Jatim Terkait } \\
\text { Prostitusi Artis, Jumat akan Dipanggil Lagi }\end{array}$ & $\begin{array}{l}\text { https://jatim.tribunnews.com/2019/01/21/vanessa- } \\
\text { angel-mangkir-dari-panggilan-polda-jatim-terkait- } \\
\text { prostitusi-artis-jumat-akan-dipanggil-lagi }\end{array}$ \\
\hline 4 & $\begin{array}{l}\text { Nama Baru } 21 \text { Artis Saksi Kasus Prostitusi } \\
\text { Online, Ada yang Terbukti Pernah Lakukan } \\
\text { Transanksi }\end{array}$ & $\begin{array}{l}\text { https://jatim.tribunnews.com/2019/01/21/nama-baru- } \\
20 \text {-artis-saksi-kasus-prostitusi-online-ada-yang- } \\
\text { terbukti-pernah-lakukan-transanksi }\end{array}$ \\
\hline 5 & $\begin{array}{l}\text { Ibu Sambung VA Tanggapi Kabar Putrinya } \\
\text { yang Terjerat Prostitusi Online karena Utang }\end{array}$ & $\begin{array}{l}\text { https://jatim.tribunnews.com/2019/01/23/ibu- } \\
\text { sambung-vanessa-angel-tanggapi-kabar-putrinya- } \\
\text { yang-terjerat-prostitusi-online-karena-utang }\end{array}$ \\
\hline 6 & $\begin{array}{l}\text { Hari ini, Polda Jatim Panggil VA Soal Kasus } \\
\text { Prostitusi, Polisi: Ditahan atau Tidak Monggo }\end{array}$ & $\begin{array}{l}\text { https://jatim.tribunnews.com/2019/01/25/hari-ini- } \\
\text { polda-jatim-panggil-vanessa-angel-soal-kasus- } \\
\text { prostitusi-polisi-ditahan-atau-tidak-monggo }\end{array}$ \\
\hline 7 & $\begin{array}{l}\text { Ayah VA Bongkar Masa Lalu Anaknya Terkait } \\
\text { Keluarga: Kabur dan } 10 \text { Tahun Tinggalkan } \\
\text { Rumah }\end{array}$ & $\begin{array}{l}\text { https://jatim.tribunnews.com/2019/01/25/ayah- } \\
\text { vanessa-angel-bongkar-masa-lalu-anaknya-terkait- } \\
\text { keluarga-kabur-dan-10-tahun-tinggalkan-rumah }\end{array}$ \\
\hline 8 & $\begin{array}{l}\text { VA Batal Diperiksa di Polda, Sakit Usai } \\
\text { Ditetapkan Tersangka Prostitusi Online }\end{array}$ & $\begin{array}{l}\text { https://jatim.tribunnews.com/2019/01/25/vanessa- } \\
\text { angel-batal-diperiksa-di-polda-sakit-usai-ditetapkan- } \\
\text { tersangka-prostitusi-online }\end{array}$ \\
\hline 9 & $\begin{array}{l}\text { VA Diduga Takut Ditahan Hingga Tidak } \\
\text { Berani Ke Polda Jatim }\end{array}$ & $\begin{array}{l}\text { https://jatim.tribunnews.com/2019/01/26/vanessa- } \\
\text { angel-diduga-takut-ditahan-hingga-tidak-berani-ke- } \\
\text { polda-jatim }\end{array}$ \\
\hline 10 & $\begin{array}{l}\text { Didi Mahardika Sang Mantan Tunangan } \\
\text { Ternyata Pernah Minta Maaf ke Ayah VA }\end{array}$ & $\begin{array}{l}\text { https://jatim.tribunnews.com/2019/01/26/didi- } \\
\text { mahardika-sang-mantan-tunangan-ternyata-pernah- } \\
\text { minta-maaf-ke-ayah-vanessa-angel }\end{array}$ \\
\hline 11 & $\begin{array}{l}\text { VA Akhirnya Ketemu Doddy Sudrajat Sang } \\
\text { Ayah, Tampak Lebih Kurus dan Cipika-cipiki }\end{array}$ & $\begin{array}{l}\text { https://jatim.tribunnews.com/2019/01/26/vanessa- } \\
\text { angel-akhirnya-ketemu-doddy-sudrajat-sang-ayah- } \\
\text { tampak-lebih-kurus-dan-cipika-cipiki }\end{array}$ \\
\hline 12 & $\begin{array}{l}\text { Gaya Hidup VA Ditelusuri Adiknya Lewat IG, } \\
\text { Ayahnya Emosi Lihat Perlakuannya ke Sang } \\
\text { Adik }\end{array}$ & $\begin{array}{l}\text { https://jatim.tribunnews.com/2019/01/26/gaya- } \\
\text { hidup-vanessa-angel-ditelusuri-adiknya-lewat-ig- } \\
\text { ayahnya-emosi-lihat-perlakuannya-ke-sang-adik }\end{array}$ \\
\hline 13 & $\begin{array}{l}\text { VA Mengaku Honornya Dulu Dikendalikan } \\
\text { Sang Ayah, Doddy Sudrajat Beri Pengakuan } \\
\text { Lain }\end{array}$ & $\begin{array}{l}\text { https://jatim.tribunnews.com/2019/01/26/vanessa- } \\
\text { angel-mengaku-honornya-dulu-dikendalikan-sang- } \\
\text { ayah-doddy-sudrajat-beri-pengakuan-lain }\end{array}$ \\
\hline 14 & $\begin{array}{l}\text { VA Pernah Kabur ke Rumah Kartika Putri } \\
\text { Gara-gara Ribut Soal Cowok }\end{array}$ & $\begin{array}{l}\text { https://jatim.tribunnews.com/2019/01/26/vanessa- } \\
\text { angel-pernah-kabur-ke-rumah-kartika-putri-gara- } \\
\text { gara-ribut-soal-cowok }\end{array}$ \\
\hline 15 & $\begin{array}{l}\text { VA Saat Meniti Karier Jadi Artis Dibantu } \\
\text { Orangtua, Sang Ayah Sampai Rela Jual Banyak } \\
\text { Toko }\end{array}$ & $\begin{array}{l}\text { https://jatim.tribunnews.com/2019/01/26/vanessa- } \\
\text { angel-saat-meniti-karier-jadi-artis-dibantu-orangtua- } \\
\text { sang-ayah-sampai-rela-jual-banyak-toko }\end{array}$ \\
\hline 16 & $\begin{array}{l}\text { Ceritakan Tingkah VA, Sang Ayah Geleng- } \\
\text { geleng Kepala dan Mengaku Geram: Dilihat } \\
\text { Adiknya }\end{array}$ & $\begin{array}{l}\text { https://jatim.tribunnews.com/2019/01/26/ceritakan- } \\
\text { tingkah-vanessa-angel-sang-ayah-geleng-geleng- } \\
\text { kepala-dan-mengaku-geram-dilihat-adiknya }\end{array}$ \\
\hline 17 & $\begin{array}{l}\text { Tak Tinggal dengan VA, Sang Ayah Curhat } \\
\text { Soal Putrinya yang Kabur } 10 \text { Tahun Lalu }\end{array}$ & $\begin{array}{l}\text { https://jatim.tribunnews.com/2019/01/26/tak- } \\
\text { tinggal-dengan-vanessa-angel-sang-ayah-curhat- } \\
\text { soal-putrinya-yang-kabur-10-tahun-lalu }\end{array}$ \\
\hline 18 & $\begin{array}{l}\text { Sikap VA Kepada Sang Adik Dibeberkan } \\
\text { Ayahnya: Saya Emosi kalau Sudah Ngomong } \\
\text { Mayang }\end{array}$ & $\begin{array}{l}\text { https://jatim.tribunnews.com/2019/01/27/ceritakan- } \\
\text { sikap-vanessa-angel-kepada-sang-adik-doddy-saya- } \\
\text { emosi-kalau-sudah-ngomong-mayang }\end{array}$ \\
\hline
\end{tabular}


19 Sebut VA Kirim Uang ke Sang Ayah, Pengacara Ungkap Bukti Transfer: Setiap Bulannya Jutaan

20 VA Pernah Kabur dari Rumah Gara-gara Cowok yang Dikenal di Facebook, Malah Berakhir Apes

21 Gaya Hidup VA: Perubahan Dipicu Kematian Ibunya hingga Merasa Dipaksa Kerja oleh Ayahnya

22 Sederet Artis dan Tersangka VA Akan Diperiksa di Polda Jatim

23 Jelang Diperiksa, VA dan Artis Saksi Lain Tak Kunjung Datang ke Polda Jatim hingga Siang

24 Baby Shu \& 4 Artis Bakal Diperiksa Hari Ini Soal Prostitusi Online, VA Masih Mangkir

25 Pakai Alphard Putih, VA Datangi Polda Jatim, Tergopoh-Gopoh Masuk Ruang Penyidik

26 VA Datangi Polda Jatim Pakai Alphard Putih, 4 Seleb Saksi Prostitusi Lainnya Belum Datang

27 VA ke Polda Jatim untuk Wajib Lapor Kasus Prostitusi Artis \& Bakal Diperiksa Rabu

28 Lusa Diperiksa Polda Jatim Terkait Kasus Prostitusi, VA akan Menginap di Surabaya

29 Beber Aliran Dana Prostitusi, Muncikari Dapat Transfer Rp 105 Juta, VA Dapat Rp 35 Juta

30 Kasus Prostitusi Artis, Polda Jatim Belum Bisa Pastikan Wacana Ditahannya VA

31 VA Datangi Polda Jatim Untuk Wajib Lapor, Hanya Berucap Terimakasih Lalu Pulang

32 Didi Mahardika Sang Mantan Tanggapi VA yang Terjerat Prostitusi Online: Sangat Sensitif

33 Pacar Ungkap Momen Terakhir VA Jual Mobil Demi Lanjutkan Hidup: Tangis Ditutupi Senyuman

34 Bibi Ardiansyah Pacar VA Beri Pesan Menohok Bahas Soal Ayah: Jaga Aib Anak Lu

35 Bibi Ardiansyah Bantah Jadi Penghalang Doddy Sudrajat Bertemu VA: Kenapa Aku Harus Marah?

36 VA Diperiksa Sebagai Tersangka Kasus Prostitusi Online UU ITE di Polda Jatim

37 VA Bakal Ditahan Karena Kasus Prostitusi Artis, Polda Jatim: Kemungkinan Besar https://jatim.tribunnews.com/2019/01/27/sebutvanessa-angel-kirim-uang-ke-sang-ayah-pengacaraungkap-bukti-transfer-setiap-bulannya-jutaan https://jatim.tribunnews.com/2019/01/27/vanessaangel-pernah-kabur-dari-rumah-gara-gara-cowokyang-dikenal-di-facebook-malah-berakhir-apes https://jatim.tribunnews.com/2019/01/28/gayahidup-vanessa-angel-perubahan-dipicu-kematianibunya-hingga-merasa-dipaksa-kerja-oleh-ayahnya https://jatim.tribunnews.com/2019/01/28/sederetartis-dan-tersangka-vanessa-angel-akan-diperiksadi-polda-jatim https://jatim.tribunnews.com/2019/01/28/jelangdiperiksa-vanessa-angel-dan-artis-saksi-lain-takkunjung-datang-ke-polda-jatim-hingga-siang https://jatim.tribunnews.com/2019/01/28/baby-shu4-artis-bakal-diperiksa-hari-ini-soal-prostitusionline-vanessa-angel-masih-mangki

https://jatim.tribunnews.com/2019/01/28/pakaialphard-putih-vanessa-angel-datangi-polda-jatimtergopoh-gopoh-masuk-ruang-penyidik https://jatim.tribunnews.com/2019/01/28/pakaialphard-putih-vanessa-angel-datangi-polda-jatimtergopoh-gopoh-masuk-ruang-penyidik

https://jatim.tribunnews.com/2019/01/28/vanessaangel-ke-polda-jatim-untuk-wajib-lapor-kasusprostitusi-artis-bakal-diperiksa-rabu

https://jatim.tribunnews.com/2019/01/28/lusadiperiksa-polda-jatim-terkait-kasus-prostitusivanessa-angel-akan-menginap-di-surabaya https://jatim.tribunnews.com/2019/01/28/beberaliran-dana-prostitusi-muncikari-dapat-transfer-rp105-juta-vanessa-angel-dapat-rp-35-juta https://jatim.tribunnews.com/2019/01/28/kasusprostitusi-artis-polda-jatim-belum-bisa-pastikanwacana-ditahannya-vanessa-angel

https://jatim.tribunnews.com/2019/01/28/vanessaangel-datangi-polda-jatim-untuk-wajib-lapor-hanyaberucap-terimakasih-lalu-pulang

https://jatim.tribunnews.com/2019/01/30/kondisiterkini-vanessa-angel-tak-ada-duit-tinggal-di-koshingga-jual-mobil-yang-belum-lunas https://jatim.tribunnews.com/2019/01/30/pacarungkap-momen-terakhir-vanessa-angel-jual-mobildemi-lanjutkan-hidup-tangis-ditutupi-senyuman https:/jatim.tribunnews.com/2019/01/30/bibiardiansyah-pacar-vanessa-angel-beri-pesanmenohok-bahas-soal-ayah-jaga-aib-anak-lu https://jatim.tribunnews.com/2019/01/30/bibiardiansyah-bantah-jadi-penghalang-doddy-sudrajatbertemu-vanessa-angel-kenapa-aku-harus-marah https://jatim.tribunnews.com/2019/01/30/vanessaangel-diperiksa-sebagai-tersangka-kasus-prostitusionline-uu-ite-di-polda-jatim

https://jatim.tribunnews.com/2019/01/30/vanessaangel-bakal-ditahan-karena-kasus-prostitusi-artispolda-jatim-kemungkinan-besar 
38 VA Jalani Pemeriksaan di Polda Jatim Didampingi Tante dan Kuasa Hukumnya

39 VA Tersangka Kasus Prostitusi, Tantenya Ceritakan Saat Masih Kecil: 18 Tahun Berjalan

40 Alasan Tante VA Temani Sang Ponakan di Polda Jatim Pasca 18 Tahun Tak Berhubungan

41 Tante VA Ngaku Bakal Support VA Hadapi Kasusnya: Dijalani Saja

42 Breaking News: VA Resmi Ditahan Polda Jatim, Sesuai Syarat Objektif dan Alasan Subjektif

43 Mengintip Spesifikasi Porsche Boxster, Mobil Sport Milik VA yang Dijual dan Belum Lunas

44 UPDATE - Alasan Polda Jatim Penjarakan VA, Hilangkan Barang Bukti hingga Melarikan Diri

45 Update Kasus Prostitusi Online, Artis VA akan Jalani Masa Tahanan 20 Hari di Polda Jatim

46 VIDEO: Klarifikasi Polda Jatim Terkait Penahanan Artis VA dalam Kasus Prostitusi Artis

47 Jadi Tersangka, VA Nangis Saat Disidik Polisi, Ditempatkan di Sel Khusus di Polda Jatim

48 Sakit, VA Dilarikan ke Rumah Sakit Bhayangkara Surabaya usai 12 Jam Diperiksa Polisi

49 VA Dievakuasi Kursi Roda Saat Tiba di RS Bhayangkara Surabaya

50 Beginilah Kondisi Kesehatan VA Pasca Jatuh Pingsan di Polda Jatim

51 VIDEO - Detik Detik VA Lemas, Baju Basah Lalu Pingsan, Pria Tinggi Besar Coba Buka Jalan

52 VA Resmi Ditahan Polda Jatim, Reaksi Doddy Sudrajat Sang Ayah: Memang Prosedurnya

53 Orangtua Bibi Ardiansyah Awalnya Sempat Sinis Sama VA, Dikira Bandel dan Susah Diatur

54 Bibi Ardiansyah Ungkap Orangtuanya Awalnya Sinis ke VA, Luluh karena Sikap Tulus Echa

55 Ruben Onsu Sang Mantan Kekasih Puji Sifat Asli Doddy Sudrajat Ayah VA yang Penyabar

56 Jane Shalimar Dibuat Murka oleh Bibi Ardiansyah Kekasih VA: Songong Bener Ya? https://jatim.tribunnews.com/2019/01/30/vanessaangel-jalani-pemeriksaan-di-polda-jatimdidampingi-tante-dan-kuasa-hukumnya https://jatim.tribunnews.com/2019/01/30/vanessaangel-tersangka-kasus-prostitusi-tantenya-ceritakansaat-masih-kecil-18-tahun-berjalan

https://jatim.tribunnews.com/2019/01/30/alasantante-vanessa-angel-temani-sang-ponakan-di-poldajatim-pasca-18-tahun-tak-berhubungan https://jatim.tribunnews.com/2019/01/30/tantevanessa-angel-ngaku-bakal-support-vanessa-angelhadapi-kasusnya-dijalani-saja

https://jatim.tribunnews.com/2019/01/30/breakingnews-vanessa-angel-resmi-ditahan-polda-jatimsesuai-syarat-objektif-dan-alasan-subjektif https://jatim.tribunnews.com/2019/01/30/mengintipspesifikasi-porsche-boxster-mobil-sport-milikvanessa-angel-yang-dijual-dan-belum-lunas https://jatim.tribunnews.com/2019/01/30/updatekasus-prostitusi-online-artis-vanessa-angel-akanjalani-masa-tahanan-20-hari-di-polda-jatim https://jatim.tribunnews.com/2019/01/30/updatekasus-prostitusi-online-artis-vanessa-angel-akanjalani-masa-tahanan-20-hari-di-polda-jatim https://jatim.tribunnews.com/2019/01/30/videoklarifikasi-polda-jatim-terkait-penahanan-artisvanessa-angel-dalam-kasus-prostitusi-artis https://jatim.tribunnews.com/2019/01/30/jaditersangka-vanessa-angel-nangis-saat-disidik-polisiditempatkan-di-sel-khusus-di-polda-jatim https://jatim.tribunnews.com/2019/01/31/sakitvanessa-angel-dilarikan-ke-rumah-sakitbhayangkara-surabaya-usai-12-jam-diperiksa-polisi https://jatim.tribunnews.com/2019/01/31/vanessaangel-dievakuasi-kursi-roda-saat-tiba-di-rsbhayangkara-surabaya

https://jatim.tribunnews.com/2019/01/31/beginilahkondisi-kesehatan-vanessa-angel-pasca-jatuhpingsan-di-polda-jatim

https://jatim.tribunnews.com/2019/01/31/videodetik-detik-vanessa-angel-lemas-baju-basah-lalupingsan-pria-tinggi-besar-coba-buka-jalan https://jatim.tribunnews.com/2019/01/31/vanessaangel-resmi-ditahan-polda-jatim-reaksi-doddysudrajat-sang-ayah-memang-prosedurnya https://jatim.tribunnews.com/2019/01/31/orangtuabibi-ardiansyah-awalnya-sempat-sinis-samavanessa-angel-dikira-bandel-dan-susah-diatur https://jatim.tribunnews.com/2019/01/31/bibiardiansyah-ungkap-orangtuanya-awalnya-sinis-kevanessa-angel-luluh-karena-sikap-tulus-echa https://jatim.tribunnews.com/2019/01/31/rubenonsu-sang-mantan-kekasih-puji-sifat-asli-doddysudrajat-ayah-vanessa-angel-yang-penyabar https://jatim.tribunnews.com/2019/01/31/janeshalimar-dibuat-murka-oleh-bibi-ardiansyahkekasih-vanessa-angel-songong-bener-ya 


\section{Polda Jatim Beri Toleransi Penundaan Penahanan VA}

58 kabar Terkini VA: Penahanan Ditunda, Polda Jatim: Ini Faktor Kemanusiaan \& Kesehatan

59 Mami Eko Sediakan Teman Tidur Via Whatsapp, Sempat Galau Saat VA Ditangkap

60 Meski Masih Dirawat di Rumah Sakit, VA Kini Resmi Jadi Tahanan Polda Jatim

61 Sudah Tersangka, VA Dirawat di RS Bhayangkara Surabaya, Kondisi Lemas dan Pakai Infus

62 Drop Saat Pemeriksaan Hingga Dirawat di RS Bhayangkara Surabaya, VA Derita Sinus dan Maag https://jatim.tribunnews.com/2019/01/31/poldajatim-beri-toleransi-penundaan-penahanan-vanessaangel

https://jatim.tribunnews.com/2019/01/31/penahananvanessa-angel-ditunda-polda-jatim-ungkapsebabnya-ini-situasional-jadi-ya-tidak-bisa https://jatim.tribunnews.com/2019/01/31/mami-ekosediakan-teman-tidur-via-whatsapp-sempat-galausaat-vanessa-angel-ditangkap

https://jatim.tribunnews.com/2019/01/31/meskimasih-dirawat-di-rumah-sakit-vanessa-angel-kiniresmi-jadi-tahanan-polda-jatim https://jatim.tribunnews.com/2019/01/31/sudahtersangka-vanessa-angel-dirawat-di-rs-bhayangkarasurabaya-kondisi-lemas-dan-pakai-infus https://jatim.tribunnews.com/2019/01/31/drop-saatpemeriksaan-hingga-dirawat-di-rs-bhayangkarasurabaya-vanessa-angel-derita-sinus-dan-maag

Sumber: jatim.tribunnews.com

\section{HASIL PENELITIAN}

Media harus memiliki tanggung jawab untuk melindungi korban kekerasan seksual untuk mengurangi rasa traumatik korban. Kode etik telah mengatur pentingnya melindungi privasi korban kejahatan seksual yang melibatkan perempuan dan anak. Kode Etik Jurnalistik Pasal 2 menyatakan: "Wartawan Indonesia menempuh cara-cara yang profesional dalam melaksanakan tugas jurnalistik" pada tafsirannya menyatakan, wartawan dilarang menampilkan indetitas narasumber, dan memberitakan secara berimbang, serta menghormati pengalaman traumatik narasumber.

Dari 62 berita yang memuat prostitusi online yang melibatkan artis VA, semua pemberitan menampilkan indentitas VA bersama keluarganya. Tidak ada pemberitaan yang menampilkan indentitas mukicari, pelanggan dan atau pemesan jasa prostitusi online VA. Ini menujukkan, Jatim.Tribunnews.com tidak berimbang dalam melakukan pemberitaan terkait prostitusi online VA.

Perempuan dan seks cenderung dijadikan objek untuk menarik pembaca dalam ekonomi politik media. Pasalnya, seks dan kekerasan menjadi isu yang paling laku dan mempunyai ratinggi tinggi, namun tidak mencerdaskan masyarakat. Kekerasan seksual berupa pemerkosaan, pelecehan seksual, dan penjualan perempuan, merupakan topik liputan yang banyak diminati media massa.

Sementara itu, penafsiran Kode Etik Jurnalistik Pasal 5 menyatakan, ada dua hal yang harus di lindungi indetitasnya dalam proses peliputan, yaitu korban kekerasaan dan anak-anak baik sebagai pelaku maupun sebagai korban kekerasan seksual. Selain itu indetitas yang mempermudah orang mengetahui dan melacak seseorang baik pelaku maupun korban kejahatan seksual yang melibatkan perempuan tidak boleh disebutkan.

Tabel 2. Pelanggaran Kode Etik Jurnalistik Berita Prostitusi Online VA di Jatim.Tribunnews. Com

\begin{tabular}{cll}
\hline No & Jenis Pelanggaran Kode Etik Jurnalistik & Jumlah Berita \\
\hline 1 & Menyebutkan nama lengkap VA & 62 \\
\hline 2 & Memajang foto VA & 45 \\
\hline 3 & Menampilkan Video VA & 2 \\
\hline 4 & Menyebutkan nama keluarga VA & 23 \\
\hline 5 & Menajang foto keluarga VA & 21 \\
\hline 6 & Menyebutkan dan memajang foto teman VA & 4 \\
\hline 7 & Menyebutkan dan memajang foto mantan kekasih VA & 2 \\
\hline 8 & Menyebutkan dan memajang foto kekasih VA & 5 \\
\hline
\end{tabular}

Sumber: Hasil penelitian yang telah diolah.

Dari 62 berita yang memuat prostitusi online yang melibatkan artis VA pada 21-31 Januari 2019, semua berita menyebutkan nama VA baik di judul mapun pada isi berita. Selain itu juga terdapat 45 
foto dan dua video yang menampilkan wajah VA. Hal ini menujukkan, wartawan Jatim.Tribunews.com tidak berusaha menyembunyikan indentitas VA dalam pemberitaan kasus prostitusi online tersebut.

Pemajangan foto menujukkan bahwa perempuan yang terlibat dalam kasus kejahatan seksual menjadi komoditas pemberitaan. Hal ini sejalan dengan pendapat Mandy Merck (dalam Lan, 2002) yang mengatakan salah satu bentuk bias gender dalam media adalah media tidak ragu-ragu memajang perempuan sebagai komoditas, karena media mengganggap perempuan sebagai komoditas berita.

Untuk melacak korban maupun tersangka dalam kasus asusila dan kejahatan seksual tidak hanya dengan melihat dan mengetahui nama korban maupun terangka, tetapi juga bisa juga mengetahui keluarga, teman dan kerabat korban. Dari 62 berita yang memuat prostitusi onlin VA, terdapat 23 pemberitaan di Jatim.Tribunews.com yang menyebut nama keluarga dan 21 kali pemberitaan Jatim.Tribunews.com memajang foto diri VA, ibu, ayah, dan tantenya. Bahkan, empat berita memajang foto teman VA, dua berita memajang foto mantan kekasih VA, dan lima berita memajang foto dari kekasih VA dalam Jatim.Tribunews.com.

\section{KESIMPULAN}

Hasil penelitian ini menujukkan dalam kasus pemberitaan prostitusi online artis VA, Jatim.Tribunews.com tidak menerapkan Pasal 5 Kode Etik Jurnalistik yang menyatakan Wartawan Indonesia tidak menyebutkan identitas korban kejahatan susila dan tidak menyebutkan identitas pelaku kejahatan. Upaya dalam menampilkan identitas korban masih terjadi dalam semua pemberitaan dari 21 hingga 31 Januari 2019. Baik berupa tulisan, foto video yang menampilkan nama VA, keluarganya, temannya, mantan dan kekasihnya.

Dari 62 berita yang menampilkan kasus prostitusi online yang melibatkan VA di Jatim.Tribunews.com, wartawan Jatim.Tribunews.com juga tidak menerapkan Pasal 2 UU 40 Tahun 1999 tentang Pers yang mewajibkan wartawan menjaga profesionalitas dalam proses penyajian berita, termasuk dalam melindung indetitas terangka dan korban kejahatan seksual.

\section{DAFTAR PUSTAKA}

Afridah. (2014). Pelanggaran Kode Etik Jurnalistik Pada Pemberitaan Kekerasan Seksual Terhadap Perempuan di Media Massa Cetak: Analisis Isi Surat Kabar Lampu Hijau. Jurnal Kriminologi, 10(1), 1-8 Retrieved from http://journal.ui.ac.id/index.php/jki/article/view/7512

Alexa.com. (2019). Website Portal Berita Terpopuler Di Indonesia tahun 2019, (Retrieved from : http://www.alexa.com/topsites/countries/Id)

Aliansi Jurnalis Independent. (2015). Indikator Sensitif Gender Untuk Media : Kerangka Indikator Mengukur Sensitivitas Gender pada Organisasi dan Konten Media. Jakarta. Aliansi Jurnalis Independen

Aliansi Jurnalis Independent. (2015) Etika Perlindungan Privasi dalam Peliputan Kejahatan Seksual, (Retrieved from: https://aji.or.id/read/alert-id/48/etika-perlindungan-privasi-dalam-peliputankejahat/)

Berg \& Lune. (2012). Qualitative Research Methods for the Social Sciences. Unites States of America: Pearson Education, Inc.

Bungin, Burhan. (2005). Metode Penelitian Kuantitatif. Jakarta: Prenadamedia.

Dewan Pers, (2013). Seruan Dewan Pers Tentang Pemberitaan Kasus Kejahatan Susila. Retrieved fro

Hutami, M. (2018). Framing Media Online Tribunnews.Com Terhadap Sosok Perempuan Dalam Berita Video Pornografi Depok. Jurnal Kajian Jurnalisme, 2(1), 25-43, Retrieved from http://jurnal.unpad.ac.id/kajian-jurnalisme/article/view/21072/10766

Indianto, YI (2020). Normalisasi Kekerasan Seksual Wanita di Media Online. Jurnal Komunikasi 14(20),105-118. Retrieved from https://journal.trunojoyo.ac.id/komunikasi/article/view/6806

Lan, M. (2002). Pers, Negara \& Perempuan. Jogjakarta: Kalika.

Masduki. (2004). Menjadi Broadcaster Prosesional. Yogyakarta: LKIS.

Nasrullah, R. (2017). Etnografi Virtual: Riset Komunikasi, Budaya, dan Sosioteknologi di Internet. Bandung: Simbiosa Rekatama Media.

Nielsen. (2017). Tren Baru di Kalangan Pengguna Internet di Indonesia. Retrieved from https://www.nielsen.com/id/en/press-releases/2017/tren-baru-di-kalangan-pengguna-internet-diindonesia/ 
Prisgunanto, I. (2017). Kode Etik Jurnalistik di Kalangan Wartawan Media Massa Cetak Islam. 6(2). 185-199. Retrieved from http://jurnal.unsyiah.ac.id/JKG/article/view/9329/7316

Rossy, AE. (2015). Analisis Isi Kekerasan Seksual Dalam Pemberitaan Media Online Detik.Com. Jurnal Komunikasi 7(2). 152-164, Retrieved from https://journal.untar.ac.id/index.php/komunikasi/article/view/15

Saraswati, N. (2018) Analisis Isi Berita Kekerasan Seksual Tribunnews.Com (Periode Berita Desember 2018). Ejurnal Medium UNUD, 1(2), 1-12. Retrieved from https://ojs.unud.ac.id/index.php/komunikasi/article/view/52423

Sugiyono. (2018). Metode Penelitian Kuantitatif. Bandung: Alfabeta

Tim Dailysocial.id. (2017). Laporan Daily Social Kebiasaan Membaca Berita Secara Online di Indonesia. (Retrieved from : https://dailysocial.id/post/laporan-dailysocial-kebiasaan-membacaberita-secara-online-di-indonesia/)

Wigjosoebroto, S. (1995). Kejahatan Kesusilaan dan Pelecehan Seksual dalam Prespektif Sosial Budaya. Pelecehan Seksual: Pergumulan Antara Tradisi Hukum dan Kekuasaan, Yogyakarta: Fakultas Hukum UII 